\title{
Improvement of railway performance: a study of Swedish railway infrastructure
}

\author{
Yamur K. Al-Douri ${ }^{1} \cdot$ Phillip Tretten $^{1} \cdot$ Ramin Karim $^{1}$
}

Received: 18 May 2015/Revised: 1 December 2015/ Accepted: 7 December 2015/Published online: 21 January 2016

(C) The Author(s) 2016. This article is published with open access at Springerlink.com

\begin{abstract}
The volume of rail traffic was increased by $5 \%$ from 2006 to 2010, in Sweden, due to increased goods and passenger traffic. This increased traffic, in turn, has led to a more rapid degradation of the railway track, which has resulted in higher maintenance costs. In general, degradation affects comfort, safety, and track quality, as well as, reliability, availability, speed, and overall railway performance. This case study investigated the needs of railway stakeholders responsible for analysing the track state and what information is necessary to make good maintenance decisions. The goal is to improve the railway track performance by ensuring increased availability, reliability, and safety, along with a decreased maintenance cost. Interviews of eight experts were undertaken to learn of general areas in need of improvement, and a quantitative analysis of condition monitoring data was conducted to find more specific information. The results show that by implementing a long-term maintenance strategy and by conducting preventive maintenance actions maintenance costs would be reduced. In addition to that, problems with measured data, missing data, and incorrect location data resulted in increased and unnecessary maintenance tasks. The conclusions show that proactive solutions are needed to reach the desired goals of improved safety, improved availability, and improved reliability. This also includes the
\end{abstract}

Yamur K. Al-Douri

yamur.aldouri@1tu.se

Phillip Tretten

phillip.tretten@1tu.se

Ramin Karim

ramin.karim@1tu.se

1 Division of Operation and Maintenance Engineering, Luleå University of Technology, Luleå, Sweden development of a visualisation tool and a life cycle cost model for maintenance strategies.

Keywords Condition-based maintenance $\cdot$ Condition monitoring - Maintenance - eMaintenance - Railway track

\section{Introduction}

Railway infrastructure covers a large area and is often difficult to maintain given its complexity, number of stakeholders, weather variations, and physical components designed and developed for previous traffic and track conditions. This infrastructure is divided into several components, including administration, maintenance, traffic, and new investments. Of this system, the track is the central part. The whole railway infrastructure is focused on the track; therefore, good maintenance of the track is essential. Track maintenance must consider availability, reliability, and safety, and also be cost effective [1-3]. The purpose of the track is to provide a stable, safe platform for the train to operate at various speeds. The main issues in track deterioration are deformation of the rail head, dangerous rail cracks, and damage to the sleepers, caused by speed and load of the rolling stock. The problems increase as the train speed increases, resulting in considerable negative effects on the track components' life cycle. When the track breaks down, the loss of service, property, and even of life may occur, resulting in high maintenance costs, decreased overall track performance, unsatisfied passengers, and damaged goods [3-5].

Railway maintenance is crucial for increasing safety and to reduce costs [6]. Maintenance conducted by the Swedish Transportation Authority ( $\mathrm{TrV})$ is necessary to support railway resources and facilities [3, 7]. After railway 
stakeholders consider the data and the maintenance requirements, they can make policy decisions assisting Trafikverket. For this reason, support planning is used to identify the necessary resources for the desired maintenance tasks. The goal is to increase availability and reliability, while decreasing the risk of failure [8,9]. The type of maintenance strategy to be implemented is based on the railway track components under specific conditions [10, 11]. Preventive maintenance is one of these strategies. It is used to define maintenance over predetermined time intervals or according to specific monitoring conditionbased maintenance [10]. Condition-based maintenance (CBM) is another strategy for sufficient maintenance before an impending failure; it triggers maintenance when degradation occurs in the track. To realize this, Condition Monitoring (CM) is needed. CM means that the status of the railway track condition is monitored, recorded, and reported so that maintenance actions can be conducted before a problem occurs, thus reducing breakdowns which improves the overall track performance and reduces costs $[11,12]$.

Presently, Trafikverket is responsible for gathering track condition data. Schunnesson et al. [13] described tamping, a maintenance strategy at Trafikverket, and evaluated the measurement effectiveness. Tamping aims to improve the track quality by optimising the track geometry maintenance strategy. Bergquist and Söderholm [14] proposed an approach to be used for condition assessment of tracks. This approach ensures earlier fault warnings while the traditional approach uses a control chart to assess the track twist condition. Schunnesson's strategy relies on the real track geometry data, while the approach in Ref. [14]. relies on visual inspection of the track condition. Sadeghi and Askarinejad [15] developed a new track degradation model in two formats. This model can provide better understanding of the long-term behaviour of railway track system. Vale and Ribeiro [16] proposed a condition-based maintenance model formulated as a nonlinear program that characterised the deterioration rate of the standard deviation. They simulated the deterioration rate using Monte Carlo techniques on the real data, with the goal of optimising tamping and predicting its need in ballasted tracks.

A vast amount of information generated over several parameters indicates the condition of the railway track. Controlling the information is essential to improve the quality of the information and allow stakeholders to make better decisions [17-19]. In addition, information exchanges within maintenance should be enhanced using today's digital technologies. Maintenance draws on new technologies that take advantage of the enormous data available for the railway track. It facilitates the collection, forwarding, and processing of the information for the relevant maintenance activities and stakeholders [19, 20]. Many stakeholders have a share in the system [21, 22]. The maintenance stakeholders involved in analysis and decision making are particularly interested in condition-based maintenance. They are responsible for investigating, designing, and developing the railway maintenance strategy; to make the best decisions, certain needs must be met.

The purpose of this study is to investigate the needs of maintenance stakeholders. As noted previously, they are responsible for analysis of track irregularities and maintenance decision support. The aim of this study is to find out if the stakeholders have access to robust track information and is the information acceptable for track maintenance. Additionally, potential problems in data by analysis are investigated. To fulfil this goal, the study aims to find out what data are necessary and how they are to be collected so that track performance could be improved through proactive railway track maintenance.

\section{Railway infrastructure}

Railway infrastructure is divided into technical subsystems, including substructure, track, electrical system, signalling system, and telecom system [23]. The rolling stock is treated as a different technical subsystem, depending on what is being transported, passengers or goods [1, 2]. For trains to run on time the condition of the infrastructure must be sufficient [3]. The purpose of a railway track is to provide a stable, safe, and efficiently guided platform for the train to run at various speeds with different axle loadings [24]. There are two types of railway tracks: conventional ballasted tracks and slab tracks [5]. Current studies indicate slab tracks may be more cost effective than conventional ballasted tracks, considering life cycle, maintenance cost, and traffic disruption during maintenance [25]. The slab track incurs higher initial construction costs and repair costs, but structural damage takes longer to occur [5, 25]. Most railway tracks in Sweden are of the traditional ballasted type.

Figure 1 shows the traditional ballasted rail track. The rails are made of I-shaped bars on which the rail vehicle wheels run. Smooth and comfortable rails should have lengths up to $400 \mathrm{~m}$, which are soldered together. Sleepers transfer the load from the vehicles into the ballast and are constructed of concrete. The ballast bed anchors the track, creates bearing capacity for the track, and prevents lateral and longitudinal movement [27]. The sub-ballast is the prime track foundation; it prevents vertical movements based on the thickness of the subgrade [26]. The most physical failures and/or degradation over time occur in the track. The track affects the performance of the whole system and can lead to huge failures. Failure during operation can be costly, including costs linked to loss of 


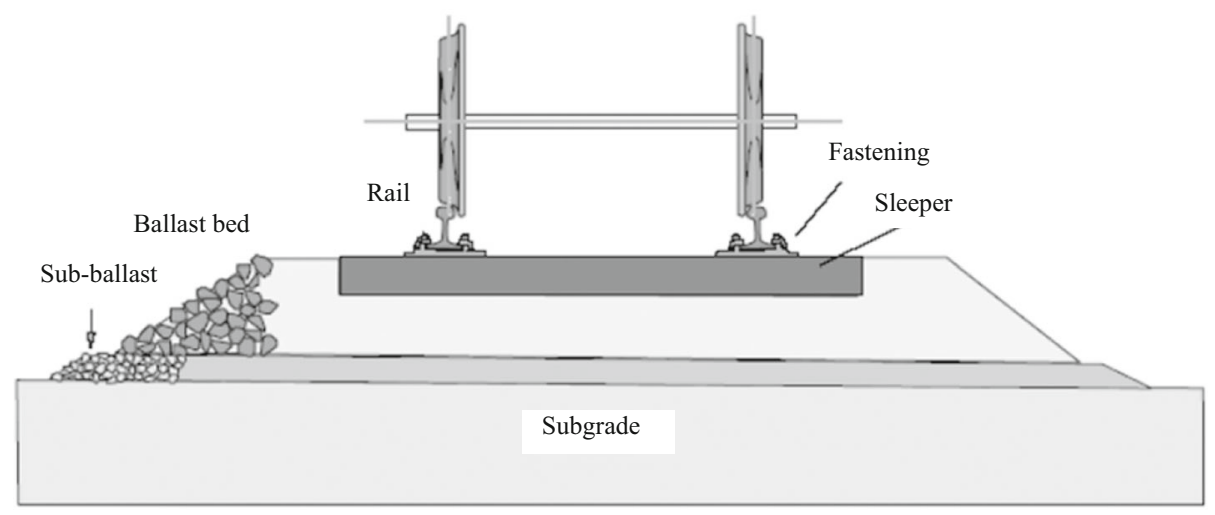

Fig. 1 Example of ballasted rail track [26]

service, property, or human life. Good track quality means lower cost and longer service life. Often, the quality is mixed because elements with different ages and statuses have to work together. Moreover, the track is not perfectly levelled and aligned; track irregularities cause the train to vibrate. Passengers are less comfortable, and goods may be damaged. This explains the need for maintenance $[3,5]$.

\subsection{Maintenance of railway infrastructure}

Proper maintenance of railway is necessary for rail traffic. The Swedish standard SS-EN 13306 p. 5 [28] defines maintenance as "the combination of all technical and administrative actions with the aim of retaining or restoring an object in such a condition as to perform its proposed function". On a basic level, maintenance is conducted on the infrastructure as reactive or proactive. Reactive maintenance refers to actions after failure has occurred, while proactive maintenance takes place at regular intervals or following certain criteria to restore the desired functionality. The maintenance objective is to minimise safety, health, environment, and financial risks [9].

Overall, maintenance plays an important role in the railway industry, supporting both safety and profit-making $[6,9]$. Maintenance support includes such resources as documentation, information, information systems, personnel, support equipment, materials, spare parts, and facilities [29]. The trend in the railway has been towards increasing automation and increasing productivity. As a result, it has become larger, more expensive, and more technically complicated than ever. The track infrastructure is a significant part of the railway system, and its maintenance plays a vital financial role in technical, administrative, and managerial decisions $[3,5,7]$.

Monitoring the condition of the railway track is part of the maintenance strategy [3, 4] and it is described as an "arrangement of the 'type' of maintenance, which is to be done to the track and its components, at a specific rate or frequency, under specific operating conditions" [3]. This can include the total life cycle, that is, costs associated with the lifetime of the track such as operating costs, maintenance costs, energy costs, and taxes. Also are included costs associated with decisions related to maintenance actions and probabilistic assessment estimations of train delay, derailment, and traffic disruption. All these consider the operational and technical aspects of the track, as well as the maintenance actions [30]. For example, by adding a life cycle costing (LCC) model for the track the total cost over its total lifespan will be calculated. It would be used to systematically process and evaluate the cost impacts of the whole life cycle of the infrastructure [3]. A LCC model is a simplified representation of a real situation in that it extracts the product cost and estimates the relationships of the products to each other and their costs in a model. Each model has its own application of the contents based on the amount of information needed and identified with the results [31].

Presently, Trafikverket is developing a LCC model of the railway infrastructure in the Mainline project [32]. This model incorporates mechanisms to estimate track deterioration with the financial and operational impacts. In this project, a tool is being developed, although not to be a fully functioning piece of software, consisting of recommendations and algorithms to be used in developing a commercial product. This Life Cycle Analysis Tool (LCAT) provides elements of Life Cycle Analysis (LCA) to assist work in railway track to justify decisions based on evidence, develop a budget for more efficient maintenance, define levels of safety and service, and predict timing for future expenditures [32].

\subsection{Condition-based maintenance for railway infrastructure}

A particular maintenance strategy should be determined for railway infrastructure components for specific operating 


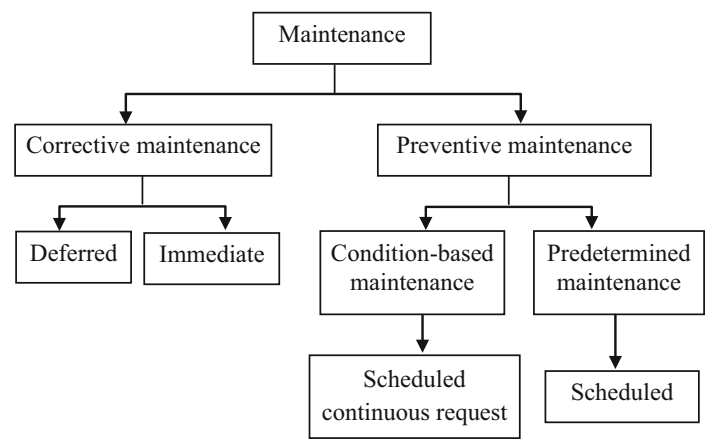

Fig. 2 Description of the maintenance strategy [10]

conditions [3]. Generally speaking, railway maintenance strategy can be one of the two types, corrective maintenance or preventive maintenance (see Fig. 2 [9]). Corrective maintenance, immediate or deferred, is carried out after fault recognition [10]. Immediate maintenance is done as soon as the fault is detected, while deferred maintenance is delayed according to given maintenance rules. Preventive maintenance takes place at predetermined intervals or according to specific criteria to reduce the probability of failure or the degradation in the functionality of the equipment. Preventive maintenance can be predetermined maintenance following established intervals of time or number of used units or condition-based maintenance [10].

Condition-based Maintenance (CBM) for the railway is a maintenance strategy that can provide sufficient warning of an impending failure. It will allow the equipment to be maintained only when there is objective evidence of failure. The methods used to monitor tracks have been improved over recent decades. Sensor fusion techniques are now commonly in use [6]. Moreover, a variety of techniques in vibration, temperature, acoustic emissions, ultrasonic, lubricant condition, and time/stress analysis have received considerable attention. The components are usually replaced or repaired as soon as the monitoring level value exceeds the normal value $[6,29]$. Track condition monitoring is an important part of CBM. Condition monitoring (CM) monitors the current railway track condition and aims to predict the future condition of the operation [33]. CM can decrease the operational risk, improve the performance, and reduce the operation cost. Being able to monitor and detect the degradation of the equipment improves the ability to prepare the necessary maintenance. The required maintenance will be performed efficiently, reducing downtime and associated costs [12, 34].

The critical part of the railway infrastructure is the track; track failures potentially affect safety and may cause delays in the speed [35]. Thus, the main objective is to ensure the performance, safety, reliability, and cost-effectiveness of the track. The inspection methods used by Trafikverket to control track irregularities and note any displacement from the design are conducted by inspection trains. The STRIX/ IMV100 monitors the track using a contactless measurement system, based on an inertial measurement system and an optical system. The measurement is based on the standard EN 13848-2. Trafikverket track condition data are collected by the measurement wagon. The wagon goes along the track at speeds up to $200 \mathrm{~km} / \mathrm{h}$ and measures each track section five to six times per year, depending on the section. Up to 35 track geometry parameters are obtained and stored for every $25 \mathrm{~cm}$ [35]. Different measurements and ways of measuring are available to assess the railway track components in direct physical contact with each other. For instance, the longitudinal level measurement is a vertical position of the right and left rails measured by a position sensor and accelerometer. The acceleration measure should be integrated vertically twice over time to determine the position of the wagon. The result is summed to identify the vertical position of each rail $[11,36]$.

To measure track condition, Trafikverket uses the $Q$ value. This value is calculated based on the standard deviation. The $Q$ value includes the contract between the rail administrator and contractor. These values show how the maintenance action is related to the maintenance strategy, i.e. corrective or preventive maintenance $[11,36]$. The measurement parameters give early warning of deterioration. The available information from the monitoring and control systems includes performance data from sensors $[10,29]$. The information generated in railway track monitoring is used to support different stakeholders. Information exchange and knowledge management affect the decisions made and the system performance [19]. Controlling the information assures better decision-making quality through information verification and improved processes [37].

In addition, ICT (Information and Communication Technology) is used to increase accessibility and usability. ICT provides several technologies to enhance information exchange over the maintenance processes. This, in turn, suggests the need to define and develop new technologies able to manage and use this information [17]. An example of ICT is the use of eMaintenance to manage railway tasks and information using digital technologies [19]. eMaintenance provides diverse benefits, for example, increased value to customers, increased availability, and reduced life cycle cost of railway track. However, developing eMaintenance requires the transformation of traditional "fail and fix" maintenance practices to a "predict and prevent" methodology [38, 39]. It can integrate production systems, operations systems, and remote customer sites, like those found in railway industry [38]. In this context, eMaintenance provides dynamic information to the customers and 
to the entire railway track system. Developing and implementing this type of system allows information to be processed in real-time. In this way, maintenance information can be used throughout the whole system life cycle [40].

\subsection{Stakeholders in condition-based maintenance}

ISO/IEC 15288 (2002) defines a stakeholder as "an interested party having a right, share or claim in the system or in its possession of characteristics that meet that party's needs and/or expectations". In this definition, the railway stakeholder is seen as a party with needs requiring appropriate actions [21]. Particular stakeholders in the railway include those involved in operation and maintenance decisions and activities [6]. CBM processes have a number of stakeholders. They may be active within this process internally or externally. Internal stakeholders perform technical and administrative actions on an item. External stakeholders are concerned with the required function of the item. Internal stakeholders may be determined by applying inductive reasoning to the condition-based maintenance process, using empirical data to develop a theory. External stakeholders may be identified by applying deductive logic to the condition-based maintenance process, using general theory to explain a specific case [21, 41]. As an example, stakeholders in condition-based maintenance are categorised in the following groups based on the Swedish railway system:

- Measurement stakeholders They are responsible for measuring the railway infrastructure using the measurement wagon. They are responsible for collecting data, filtering the measured data at different levels, and assuring the data accuracy. Their goal is to record the railway infrastructure state.

- Data quality stakeholders They are responsible to assess the data fitness to serve a specific purpose. The assessment uses statistical methods, comparing new data with previous data records. They report the data quality to the measurement stakeholders to solve problems.

- Analysis stakeholders They are responsible for analysing the incoming data using different factors. This analysis will help to identify the railway infrastructure state and decide when, where, and how maintenance should be done. A maintenance decision is made by analysing a track section. Most of the decisions are corrective maintenance.

- Decision-making stakeholders They have the responsibility for designing and developing the railway infrastructure maintenance strategy. They also define the cost of and the budget for maintenance. For instance, they plan tamping and determine the cost.
- Maintenance stakeholders They are responsible for performing the required maintenance on the infrastructure. The required action is based on the decisions of the decision-making stakeholders.

The stakeholders in condition-based maintenance are responsible for analysing the railway infrastructure state and setup and developing the maintenance strategy. Obviously, stakeholders who make decisions have certain needs; if their needs are met, in terms of the correct data gathered by selecting the correct measures, their analysis will be better, they will make better decisions, and the performance of the railway system will improve.

\section{Case study design and participants}

A case study is generally used to test assumptions and to answer specific research questions. The design of case study established the chain of evidences to create a draft of information, in order to capture the possible information. Through our case study, we seek to improve the railway infrastructure performance [41].

In what follows, first, we do a review of the literature on maintenance, condition monitoring, and condition-based maintenance. Next, we conduct a case study using mixed methods research. We use material from interviews to prepare the questions. The results help us to recognise the data, parameters, identify the problems, and determine the corresponding needs to correct the problems and improve track performance. Finally, the study analyses track condition data with respect to the identified problems/needs. The mixed study combines qualitative and quantitative approaches, with two types of data sources.

\subsection{Interviews}

Individuals interviewed held positions where they were responsible for data quality, data analysis, and maintenance decision making for Trafikverket. Eight interviewees work fulltime analysing the railway track performance, and one spends five percent of his time on analysis. Table 1 shows the participants, their position, roles, and the years of experience. The interviews were open-ended lasting from two to four hours per individual. The interviews were either face-to-face or via videoconference so as to ensure better understanding. This method also yielded a high volume of information. Some interviewees were followed up by telephone to complement missing information. Questions used served as guidelines to gain information for four different areas; data, parameters, problems, and needs. The questions are found in Appendix.

The interviews were structured around what was required by decision-making stakeholders and the problems 
Table 1 Interviewees' position, role in the organisation, and experience

\begin{tabular}{|c|c|c|c|}
\hline $\begin{array}{l}\text { No. of } \\
\text { interviewees }\end{array}$ & Position & Roles & Experience \\
\hline Interviewee 1 & Track engineer & $\begin{array}{l}\text { Developing Life Cycle Model for Railway Superstructure and } \\
\text { introducing "Standard" element which is a calculation block within } \\
\text { LCC depending on certain parameters }\end{array}$ & 10 years \\
\hline Interviewee 2 & Researcher & $\begin{array}{l}\text { Research on railway maintenance optimisation by applying } \\
\text { maintenance decision support tools (RAMS \& LCC) }\end{array}$ & 7 years \\
\hline Interviewee 3 & Track engineer & Specialist in track analysis & 13 years \\
\hline Interviewee 4 & Track maintenance engineer & $\begin{array}{l}\text { Maintenance planning, Planning of major replacements of track } \\
\text { components, Technical support to local track managers }\end{array}$ & 5 years \\
\hline Interviewee 5 & Maintenance engineer & Long-term maintenance planning and technical support & 20 years \\
\hline Interviewee 6 & Track engineer & Management leader Optram & 6 years \\
\hline Interviewee 7 & Project Manager & Project Manager of the contract for Track measurements & 9 years \\
\hline Interviewee 8 & Maintenance engineer & Presenting long-term maintenance plans & 10 years \\
\hline
\end{tabular}

they faced. The interviewer wanted to get to the point without missing important issues. The interviewees were experienced and understood the environment. All interviews were tape recorded and transcribed to make data analysis easier and capture the relevant information. The interviews results considered the expert personnel answers. The analysis of the interview data was used to make empirically based conclusions on the case study data. Specifically, the case study used a pattern matching analytic technique, comparing an empirically based pattern with a predicted one or with several alternative predictions. The pattern matching technique finds gross matches or mismatching, so interpretation is less likely to be challenged.

\subsection{Data collection and treatment}

The case study is based on the Trafikverket database Optram (optimised track management system). These data collected with a measurement vehicle, operated by a contractor, were used to observe more than 30 parameters of the track condition. The parameters are measured up to six times per year. The measurement depends on the nature of the section, such as curves or stations, and its relation to GPS positioning and kilometre markers on the track. The resulting data on track quality are divided into five classes, depending on the load and the speed $[11,12]$. Optram data consist of track geometry measurements, overhead wire measurements, real profile measurements, corrugation measurements, ballast profile measurements, ground penetrating radar, and stiffness measurements. These data are used in planning the maintenance strategy. The data have been chosen for the lines section BDL111 and BDL119 between 2007 and 2014.

The Optram track geometry parameters are longitudinal level (short, middle, and long wavelength), alignment (short, middle, and long wavelength), track gauge, cant, twist $(3 \mathrm{~m}$ and $6 \mathrm{~m})$, and the standard deviation for longitudinal level and cooperation. Each of these parameters is calculated on the EN 13848 standard. Also, the indicator identifies the track state is $Q$ value. $Q$ value is the sum of standard deviations of the cant error and the standard deviation of the average longitudinal level on the comfort limits for the acceptable standard deviation.

Track section 111 is a $130-\mathrm{km}$ section of single track from Kiruna to Riksgränsen. It is mainly used for iron ore transport, which means that this line demands much maintenance at a high cost. The train quality class is 3, $80-120 \mathrm{~km} / \mathrm{h}$, the maximum axle load is $32 \mathrm{t}$, and the annual accumulated tonnage is over 22 MGT. However, the track structure on this line section was renewed with ballast between 2006 and 2009. In addition, it should also be noted that this line is operated in extreme climate conditions, which can influence the track performance. The performance has effects on the availability and safety aspects of the track. The annual climate varies from warm summers to heavy snow, and the temperatures vary between $+27{ }^{\circ} \mathrm{C}$ and $-34{ }^{\circ} \mathrm{C}$.

The track section 119 is a $34-\mathrm{km}$ section of single track consisting of six meeting stations from Boden to Luleå. Two of these six meetings allow for passenger exchange. The traffic consists of both passenger and goods traffic, and has an annual volume corresponding to approximately 23 MGT. On average about 50 trains pass the section daily, including ore trains with an axle load of 30 tonnes, freight trains with axle loads of 22.5-25 tonnes, and passenger trains. The speed varies from $50 \mathrm{~km} / \mathrm{h}$ for loaded ore trains up to $140 \mathrm{~km} / \mathrm{h}$ for the passenger trains. Figure 3 shows the track sections 111 and 119 on the Sweden map.

The data analysis was conducted using Excel based upon measured and filtered track quality values; longitudinal level, alignment, track gauge, cant, twist, STD for 


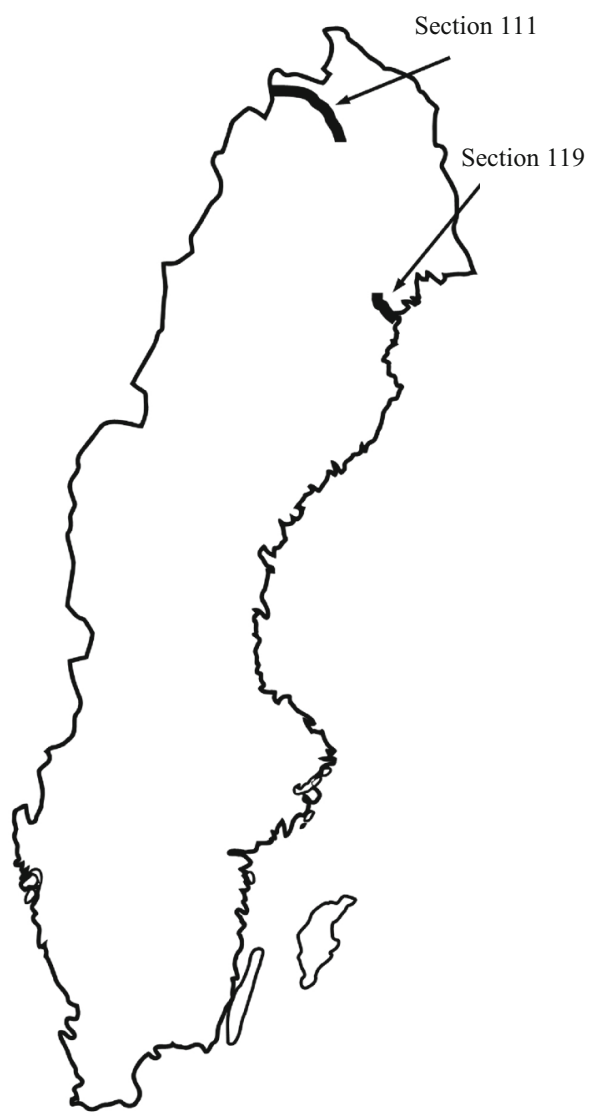

Fig. 3 Sweden map track sections 111 and 119

longitudinal level, and the relationship of track distance $(\mathrm{km})$ or over time. This study analyses longitudinal level, alignment, track gauge, cant, and twist over the kilometre. The distance was analysed for $200 \mathrm{~m}$ of each track section. This was done to gain an understanding of the track behaviour and quality for facilitating maintenance decision making. In addition, STD for longitudinal level and cooperation analyses over time was used since it aims to understand the track deviation over the years and recognise the problems from measurement or the data quality.

\section{Results and discussion}

We selected a single case study to describe the needs of stakeholders, along with the problems encountered, with the goal of improving the performance of the railway infrastructure. Ultimately, the findings should help companies make better maintenance decisions about track and asset. They will be able to define what work needs to be done, and when and where it should take place. To this end, the study correlates track data from many resources and provides features for analysing railway data. The interviews provided main four points: data, parameters, problems and analysis, and the needs of analysis and decision-making stakeholders.

\subsection{Data}

Trafikverket collects data by monitoring the infrastructure. These data are collected by many systems: assets BIS, failure system Ofelia, inspection system Bessy, track recording measuring data, and wayside monitoring systems for wheel flats and hot bearings. For the track condition data, the data quality stakeholders agree that the accuracy of data measured or calculated is good. They agree that the collaboration between different types of data measurements works well and the content accuracy is acceptable. Some stakeholders at Trafikverket are working on assuring data quality by comparing many measurements at the same time and in the same place. This will help them understand the overall situation, for example, by comparing the data of two different car measurements IMV100/EM80 and IMV200/STRIX over the same distance. Figure 4 shows the comparison of these measurements. This comparison was done using Optram data. IMV100/EM80 was measured on 12 September 2014. IMV200/STRIX was measured on 3 October 2014.

Figure 4 shows the difference between two measurements through the longitudinal level $(\mathrm{mm})$. Longitudinal level $(\mathrm{mm})$ is a parameter measured by Trafikverket to express a mean vertical position covering the wavelength ranges stipulated, and is then calculated through successive measurements. Figure 3a shows the IMV200/STRIX car has a smooth trend over the distance, with only about $2 \mathrm{~mm}$ difference in some places at the same position. Figure $3 \mathrm{~b}$ shows IMV100/EM80 has a harsh trend, with around $2 \mathrm{~m}$ shifting over the same distance measurement in some places. Car inspection uses more or less the same equipment but at different speeds or with different collaborations between car equipment. The car runs once per year. During this time, if the car inspection finds a problem, an alarm will be recorded in Optram. However, the car inspection cannot measure the data accuracy. Additionally, it recognises neither empty values nor zero values in the data; this affects processing. For this reason, measurement is uncertain, for example, when the track is covered by snow.

\subsection{Parameters}

Parameters are measurable factors setting the conditions of track operations. Trafikverket measures more than 30 parameters used in variant analysis and prediction. The analysis of parameters shows the quality of the track and indicates failures requiring maintenance. Trafikverket contractors are responsible for doing maintenance when the 

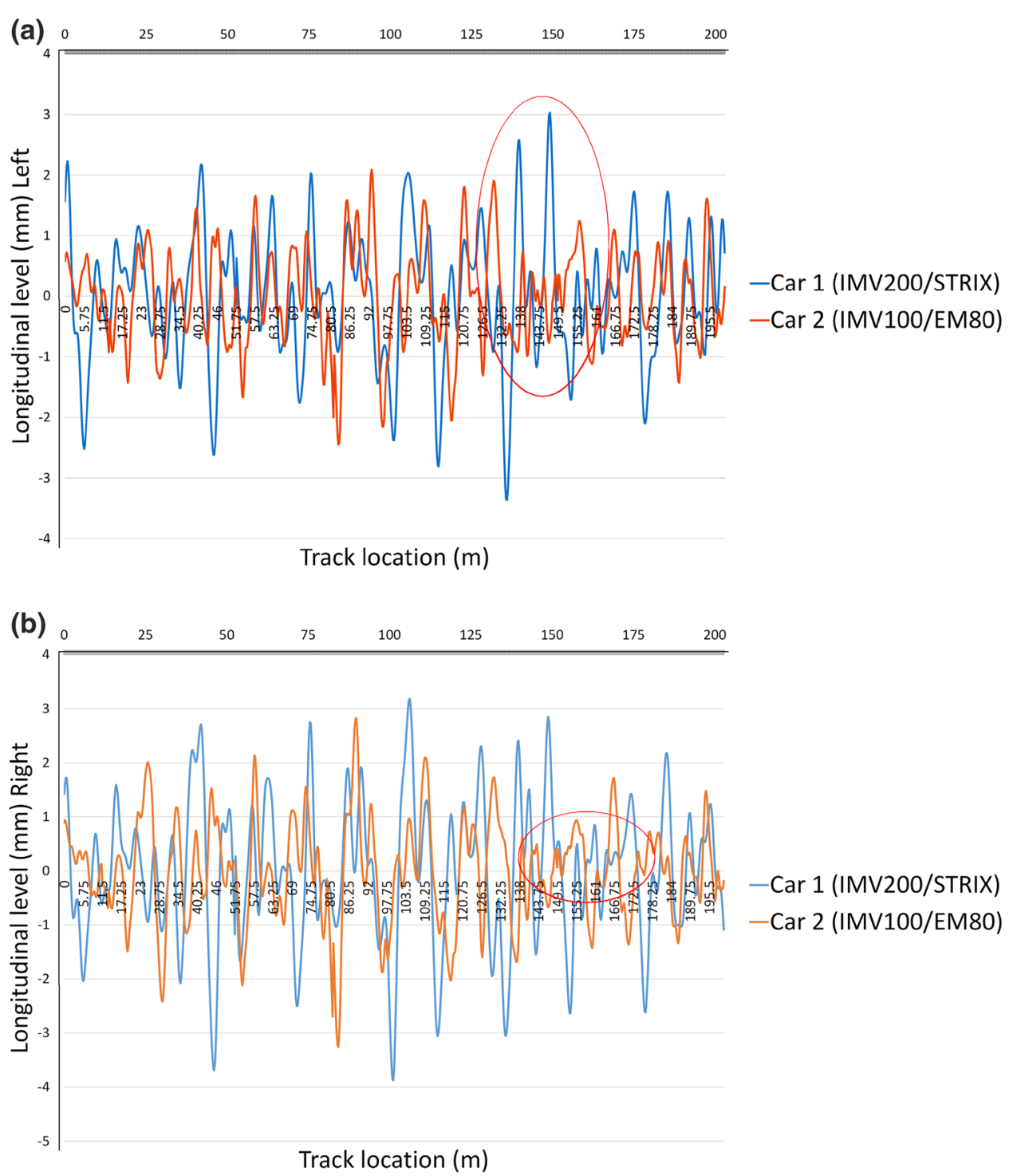

Fig. 4 Measurement of track line BDL111 at kilometre marker 1446 a from vehicle IMV100/EM80 and b from vehicle IMV200/STRIX

parameters' threshold is exceeded. Although it is difficult to know what other contractors did or how they delivered the data, the main parameters are track geometry. The degradation of these parameters is extremely dangerous; degradation also has an effect on passenger comfort. Track geometry parameters are track gauge, alignment, longitudinal level, cant (cross level), and twist. Figure 5 shows four of these parameters within a spot failure on track number 1464, measured on 29 September 2014.

Figure 5 presents the analysis of four parameters, longitudinal level, track gauge, twist, and cant of the failure spot, measuring a 200-m distance. These figures show the degradation of track performance between $13 \mathrm{~m}$ and $30 \mathrm{~m}$. Obviously, the degradation over this distance appears with the analysis of the four parameters. However, these parameters have different measurements and meanings.

- Track gauge is the distance between the gauge faces of the two adjacent running rails.

- Alignment is the mean horizontal position covering the wavelength ranges stipulated, then calculated from successive measurements.

- Longitudinal level is the mean vertical position covering the wavelength ranges stipulated, then calculated from successive measurements.

- Cant (cross level) is the height of the vertical side of the right-angled triangle related to nominal track gauge plus the width of the rail head. 


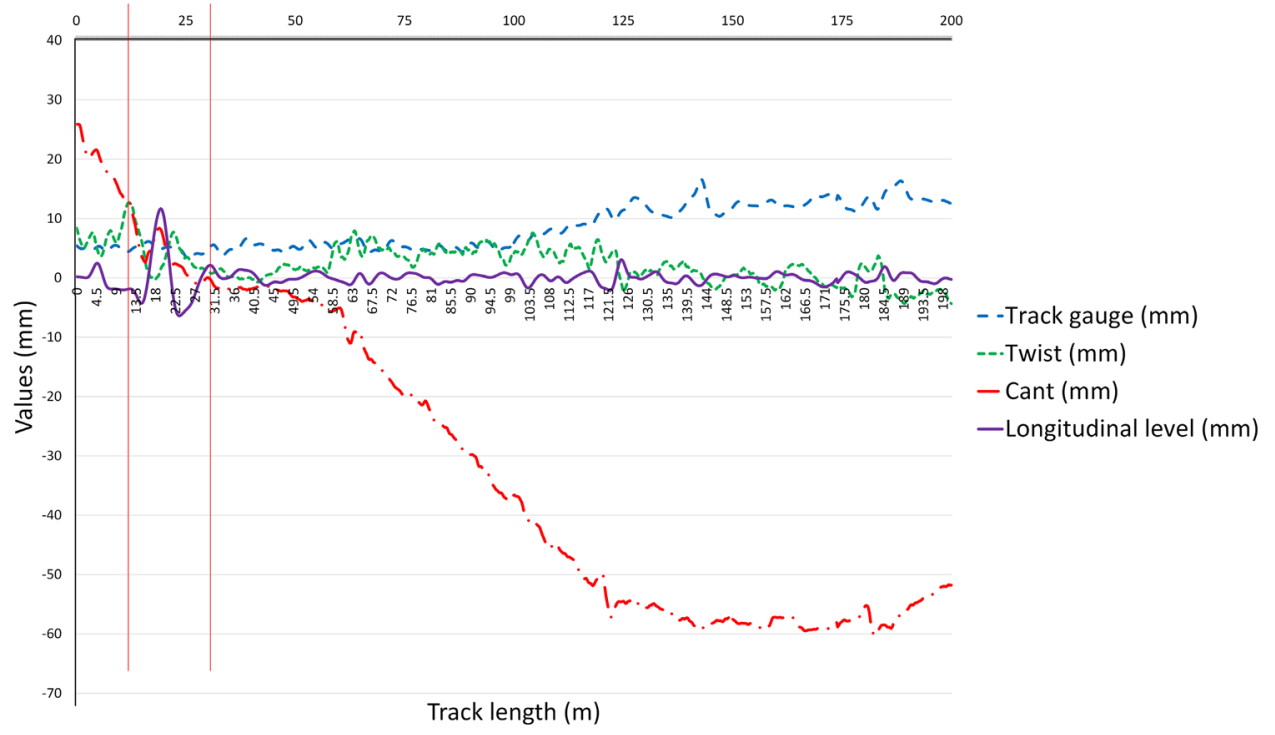

Fig. 5 Track geometry parameters for track line BDL111 km 1464 and the measurements within red column show spot failure

- Twist is the gradient between the two points of measurement.

\subsection{Problems}

Trafikverket stakeholders recognised problems after performing data analysis and comparing the historical data. Different types of analysis show the problems and give a better understanding of the nature of the problem.

\subsubsection{Positioning problems}

Positioning means finding the exact position on the track that needs maintenance. Two types of maintenance actions are considered, tamping or manual action. The positioning data are integrated from BIS (Ban Information System). BIS describes the railway in the form of nodes and links. Then, it classifies the railway into systems, areas, and distance, based on the map of Sweden. Positioning problems occur because kilometres $(\mathrm{km})$ given in the BIS system are different from reality. The positioning within kilometres $(\mathrm{km})$ is correlated using different track areas and stations. There might be additional uncertainty in measurements of alignment when the track is covered by snow. Trafikverket analysis stakeholders observed the difficulties in determining the exact position which posed a problem for doing tamping. The contractor with Trafikverket should deliver positioning of less than $5 \mathrm{~m}$, but the track positioning is currently $\pm 20 \mathrm{~m}$. Therefore, the measurement data are neither good nor accurate. This obviously appears in comparisons using other historical data for the same distance, such as longitudinal level measuring for a $200-\mathrm{m}$ distance. Figure 6 shows the positioning problem by comparing the data of 30 January 2014 and 28 May 2014 over the same 200-m distance.

Figure 6 presents the difference between these two measurements for the same track number and the same distance, around $20 \mathrm{~m}$. This difference will increase difficulties in figuring out the exact failure point; this, in turn, will increase maintenance cost. Most of the interviewees agreed that this problem has a negative effect on maintenance decision making. It might lead to wrong decisions. At the same time, uncertainty about the position might have an effect on the selection of a maintenance strategy. Other interviewees disagreed, saying that positioning is not a huge problem and does not greatly affect the maintenance decision. However, no statistical study shows the number of positioning problems over the whole data. There is some discussion about integrating a GPS system for more accurate position, but Trafikverket contractors have no desire to integrate it.

\subsubsection{Limitations of mean $Q$ value}

Calculating the mean $Q$ value could be useful to estimate the track quality, and then compare the tracks to get an idea about the budget. Figure 7 shows a $Q$ value curve over $200 \mathrm{~m}$, calculated on 29 May 2014 with the measured track length of 1464 kilometre.

Figure 7 shows the quality of the track. Over this distance, the quality is high. The quality is decided based on SS-EN13848 standard. The standard categorises the track classes; however, the $Q$ value limitation is based on an arbitrary judgment of the historical mean values. It is more 


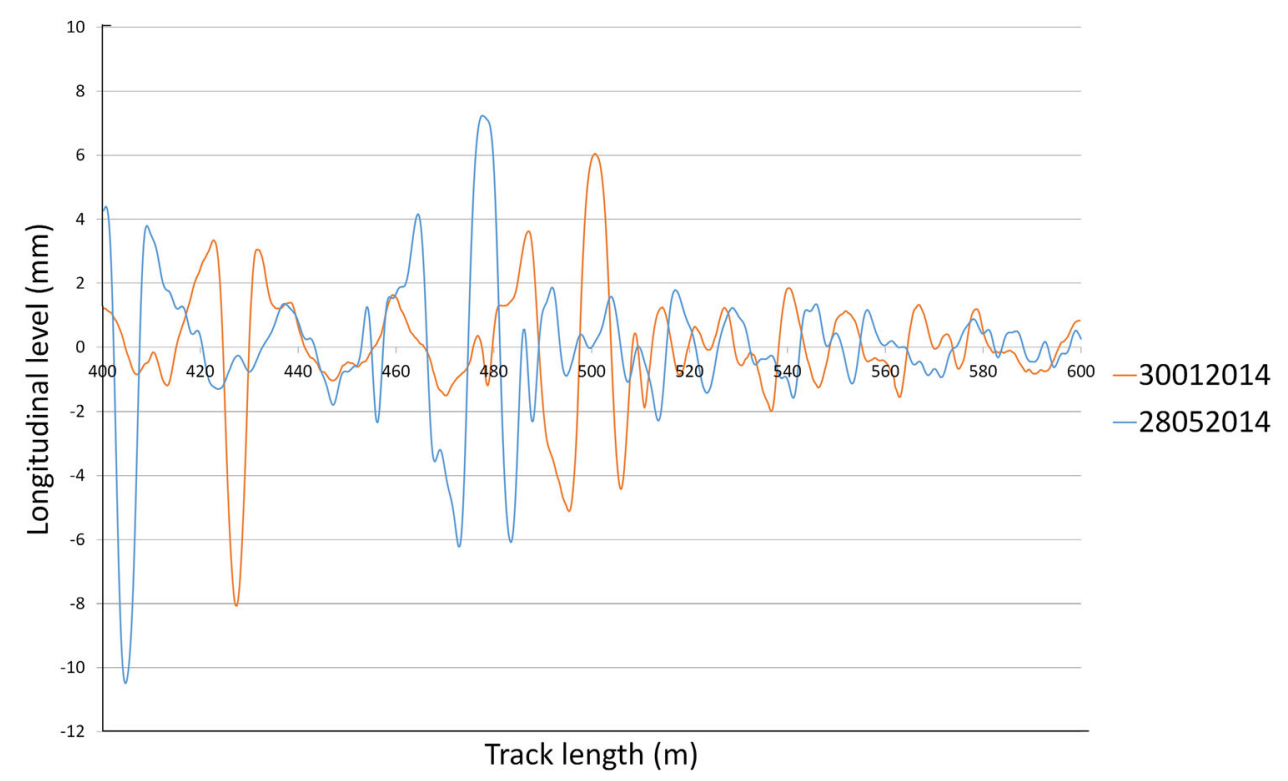

Fig. 6 Measurements of location show a variation of circa $20 \mathrm{~m}$ with the same measurement vehicle on track line BDL119 at kilometre marker 1174 in Jan and May 2014

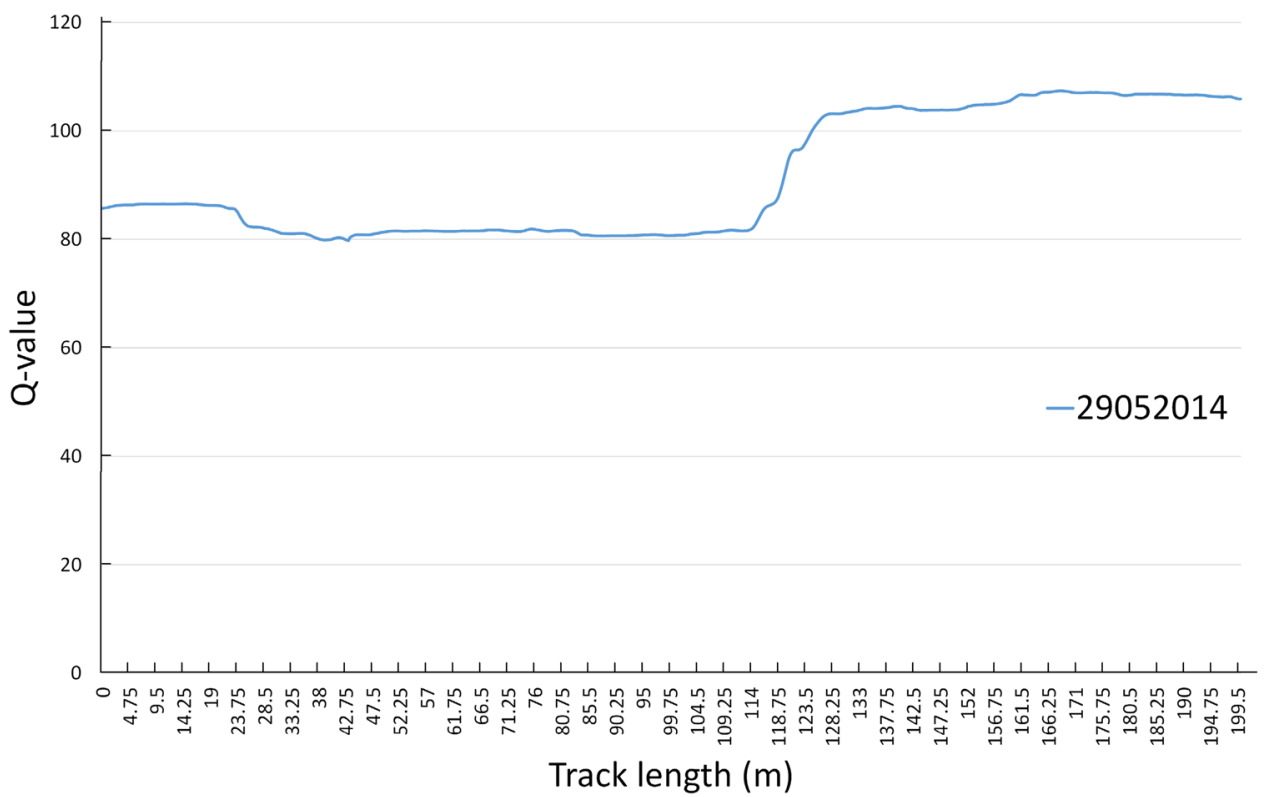

Fig. 7 Track quality $Q$ value of track line BDL111 at kilometre marker 1464

common to divide the track into small sections to get more control and detect the track quality better, but it is critical for track quality to set up an appropriate $Q$ value limit that should be maintained. The formula calculating the $Q$ value has no accurate value limits on track quality and age. Additionally, it shows the need to have more knowledge about the degradation of track quality to set up the proper limitations. The interviewees mentioned that the limit for the $Q$ value is not high. This means the performance-based contracts need to ensure a better standard and quality. Also, it is not a sure-fire method for keeping high track quality in the long run with low maintenance cost.

\subsubsection{Difficulties of analysis}

The problem is that the systems use different condition monitoring data for the railway infrastructure. Trafikverket has many systems responsible for recording all the 


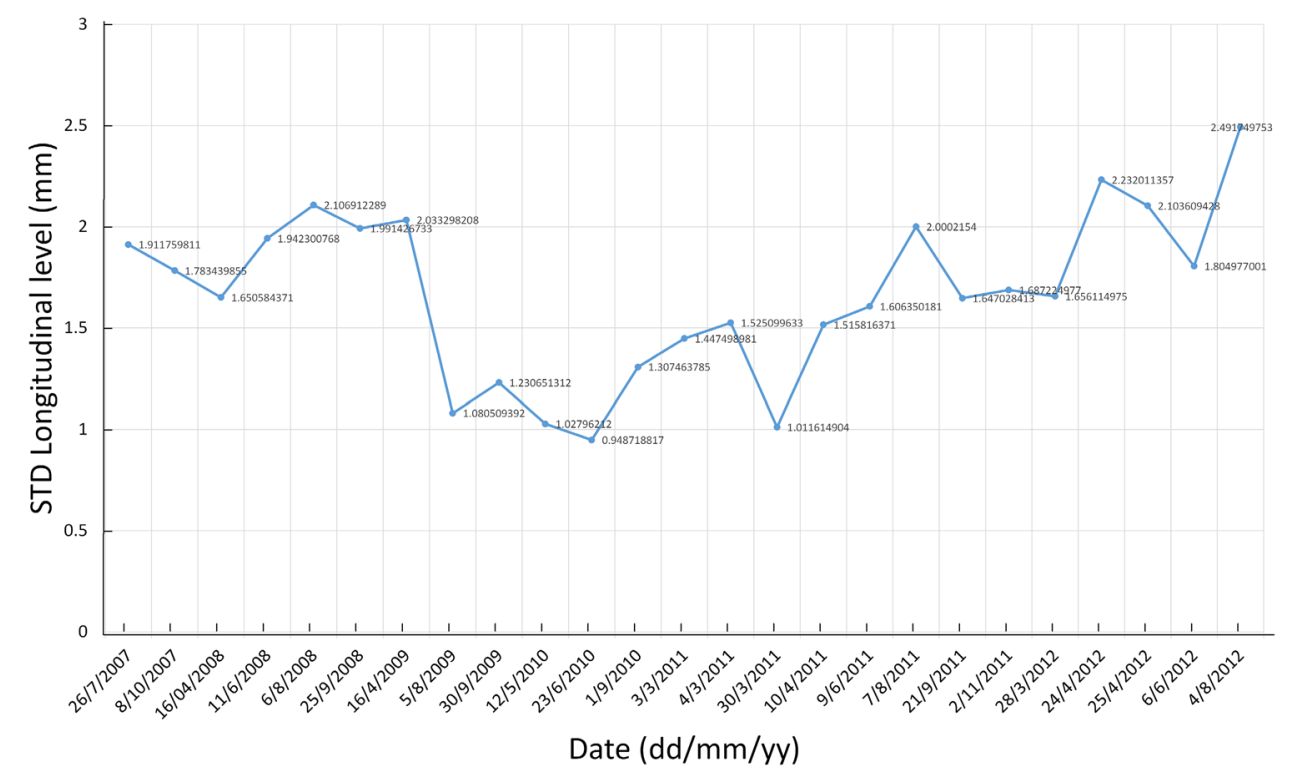

Fig. 8 Values from same track section showing variations in STD of longitudinal level from 2007 to 2012

infrastructure state. Trafikverket's software tools for analysis do not provide all the required functionalities; therefore, it is difficult to do additional analysis or calculations to better understand track degradation. Hence, different systems must be integrated. For instance, Optram can offer analysis over time or distance as shown in Fig. 8. This analysis shows the need for doing tamping based on the STD values, although specific problem and problem area are not available. Figure 8 shows the results of data from a 100-m section that was recorded between 2007 and 2012.

It is not possible to plot specific positions due to the nature of the system and the type of data available in the system. Presently, personnel export data to other tools, such as Excel, for further data analysis. However, it is still difficult to accurately analyse different track sections simultaneously. Track quality is an important analysis and for this to be done tracks must be compared.

\subsubsection{Short-term strategy}

Trafikverket has a short-term strategy whereby their contractors fulfil the demands of the $Q$ value, using corrective tamping to decrease track failure. If irregularities in ballast occur too often, Trafikverket will lose control of track quality since there is no specific long-term strategy. The cost of using the tamping machine is uncertain. Figure 9 shows the short-term strategy based on the analysis of longitudinal level (mm) on 29 May 2014. The figure suggests the need to do tamping between 18 and $25 \mathrm{~m}$. Over this distance, we see very high peaks and very low peaks. Note that longitudinal level is one of the parameters used to calculate the $Q$ value. Therefore, this variant will affect the $Q$ value.

However, throughout a year, tamping is conducted based on the track quality analysis. Yet, the results show that the analysis is inaccurate and ineffective. Therefore, discussions and on-going projects are conducted to identify future tamping plans. An example of this is that the $Q$ value has no specific limit and the measured parameters are not reliable enough to make tamping decisions. It is proposed that other measured parameters should be used to predict track degradation and determine tamping actions.

\subsubsection{Incomplete track measurement}

Incomplete track measurement has been recognised in data analysis. In such cases, the measurement wagon was supposed to measure the whole track, but was suddenly stopped or changed direction. The measurement stakeholders were supposed to ensure the continuity of the measurement wagon but sometimes they did not realize a distance was not measured. Trafikverket measures 5-6 times per year. Software tools have indicated some places are not measured. Figure 10 shows the STD of longitudinal level of $100 \mathrm{~m}$ of track. The distance between 1164,661 and $1165,561 \mathrm{~km}$ has not been measured over several measuring times: 1 January 2010, 3 March 2011, and 4 March 2011.

The measurement of the track has been disrupted, with negative effects on decision making. Some parts have not been measured, so there is no accurate assessment of track situation. 


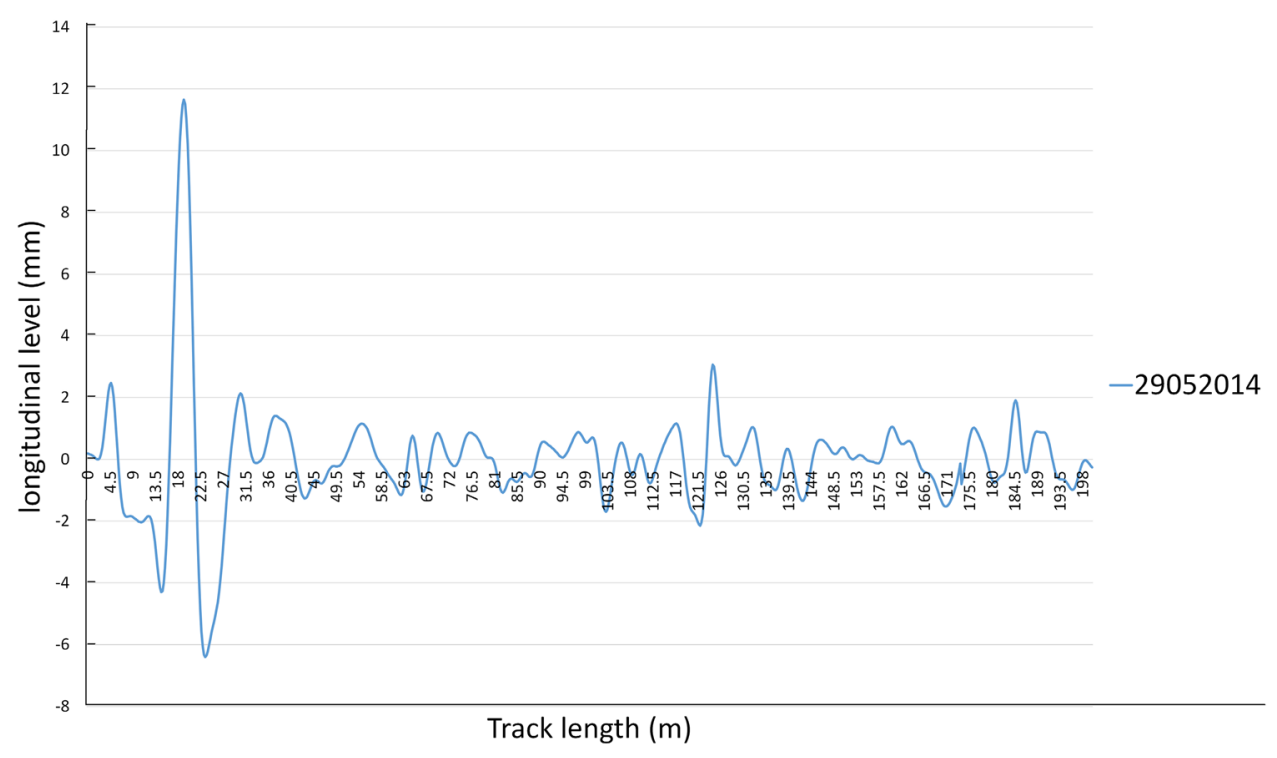

Fig. 9 The high longitudinal level variation above shows that tamping actions must be taken

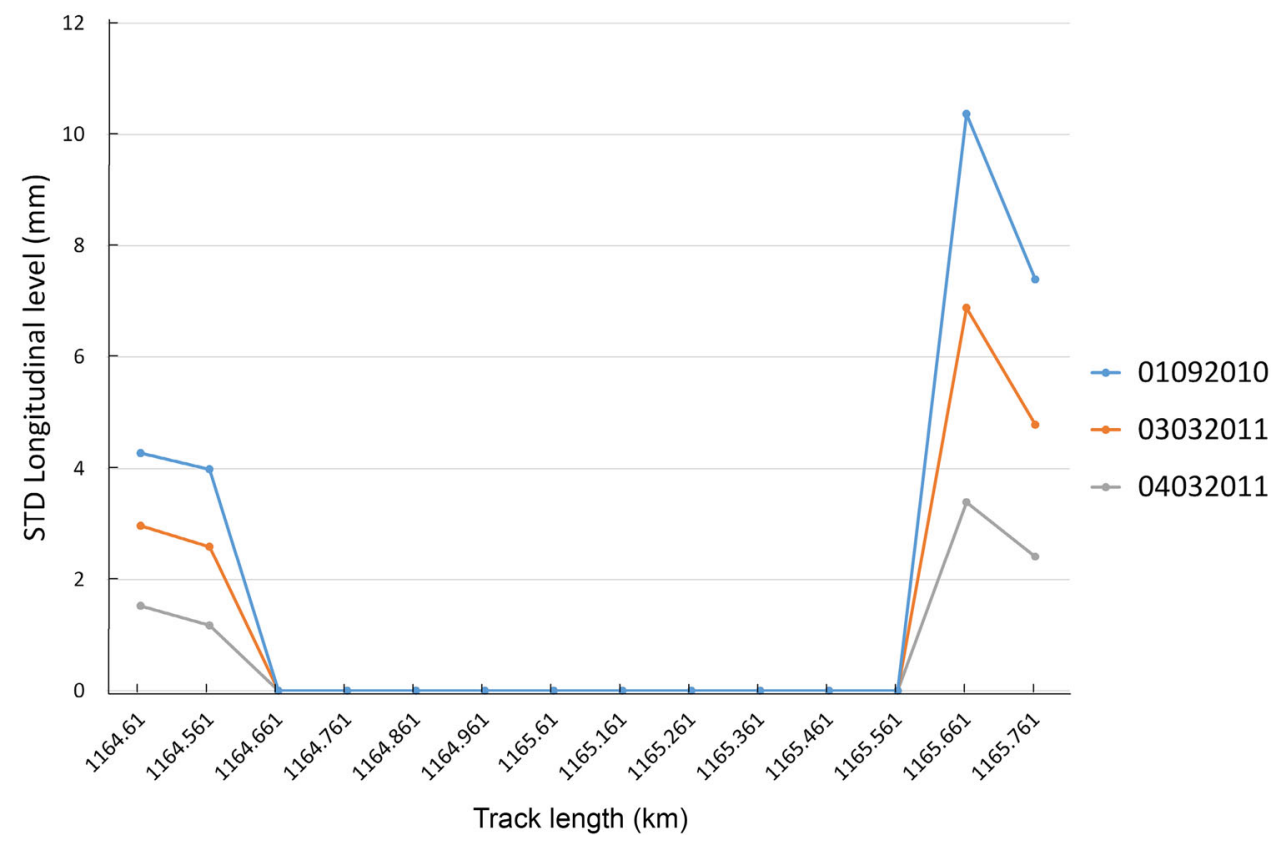

Fig. 10 STD of longitudinal level of $100 \mathrm{~m}$ of track

\subsection{Needs}

Trafikverket stakeholders that are responsible of analysis and maintenance decision making want to improve maintenance performance and decrease costs by improving analysis and prediction. If done correctly they will increase railway availability, improve safety, increase the use of resources, enhance reliability, and overall performance. As a result of this, track degradation and maintenance costs will decrease. To meet these aims, the following must happen.

\subsubsection{Analysis enhancement}

Enhance analysis by integrating data resources. Trafikverket has several data resources such as assets BIS, failure system Ofelia, inspection system Bessy, track recording measuring data, and wayside monitoring systems for wheel 
flats and hot bearings; these should be integrated into one system. This will facilitate the analysis of axle weight, speed, or total load instead of just time analysis, as shown in Fig. 8. The trends found in the analysis suggest that specific parts of the track need maintenance and give a better understanding of the situation. For instance, the analysis presents the standard deviation of alignment over time. Other factors must be considered for analysis as well, such as axle weight or speed, as these are partially to blame for failure. At the same time, a general framework capable of integrating all these systems is required. Most of the interviewees have used other software tools in Trafikverket to integrate systems and enhance analysis to assist them in maintenance decisions and estimation of maintenance costs.

\subsubsection{Further analysis}

After analysis, store the highest and lowest degradation values in the data source for each track section. Facilitate analysis based on the calculated values, to ensure better decision making and to predict track degradation. Storing the values for each track will facilitate the comparison of railway tracks. Figure 8 shows the importance of this for understanding degradation. A comparison is used to estimate the failure spot. It aims to estimate the existing problem and understand the whole performance of the railway infrastructure. One of the interviewees said he stores these values manually in an individual file for further calculation. They might help understand and minimise track degradation. As the analysis in Fig. 5 indicates, considering the parameters of two tracks can better explain the behaviour by highlighting the track situation and allowing stakeholders to compare the highest and lowest values in each track to estimate the current problem. It will also allow the stakeholders to determine the highest values on track quality and performance.

\subsubsection{Track maintenance strategy determining}

Develop and determine a maintenance strategy for each track section. Today the railway track has two maintenance strategies, either, reactive or proactive. Many software tools in Trafikverket are supposed to do proactive maintenance, but Trafikverket uses them for reactive maintenance because there is no clear limitation for maintenance cost. There is a need to shift the culture of Trafikverket, specifically among the analysis and decision-making stakeholders, from a reactive to a proactive approach. The maintenance of the railway tracks needs to integrate proactive solutions into its plan to reach the desired goal of improving safety, security, and reliability. Figure 9 shows the preferred case for deciding maintenance. Most of the interviewees said defining the strategy depends on the track degradation type. They agreed that a proactive strategy can decrease the maintenance cost and improve performance. They also said that they have a limitation for each track parameter, which has two levels UH1 and UH2 defined by the SS-EN13848 standard. The maintenance action is taken based on degradation reaching the UH1 as reactive maintenance. The UH1 values are lower than UH2. There is no reason for contractors to work on a proactive strategy when the degradation reaches $\mathrm{UH} 2$.

\subsubsection{Track maintenance planning}

Plan the maintenance for each track. Maintenance planning is done by the Trafikverket contractor. The car inspection records the faults, as shown in Fig. 4, and equates risk level to required maintenance. Corrective tamping maintenance is governed by regulations in the SS-EN13848 standard and preventive tamping should be planned in advance. There are two main aspects to consider in maintenance planning: applying for track possession time and decreasing the maintenance cost by predicting the required tamping. For instance, predicting tamping for nine months is enough time to consider the maintenance plan and budget. However, the costs depend on the distance of the track needing maintenance and the location needing maintenance. Another person claimed setting up a maintenance plan for a certain part of the track will help estimate the cost required to order the tamping machine. At the same time, it will decrease the cost and improve the track quality and performance.

\subsubsection{Time plan for maintenance action}

Create a time slot for maintenance. It is important to determine the time required for maintenance and estimate the cost required for each part of the maintenance plan. Estimating the extra time required to finalise the task is a learning process for other maintenance actions as well. Setting a time slot is crucial in estimating the time required for the maintenance plan, the extra time needed to complete the maintenance and the required cost. Determining the extra time required will help to set up a better maintenance plan.

\subsubsection{Track visualisation}

Visualise the railway track data geographically. This can be done through GPS coordinates that measures Trafikverket during the measuring track quality. The visualisation will simplify managing the railway. The mapping can show the track parts and give information on the geographic track location. This method allows 


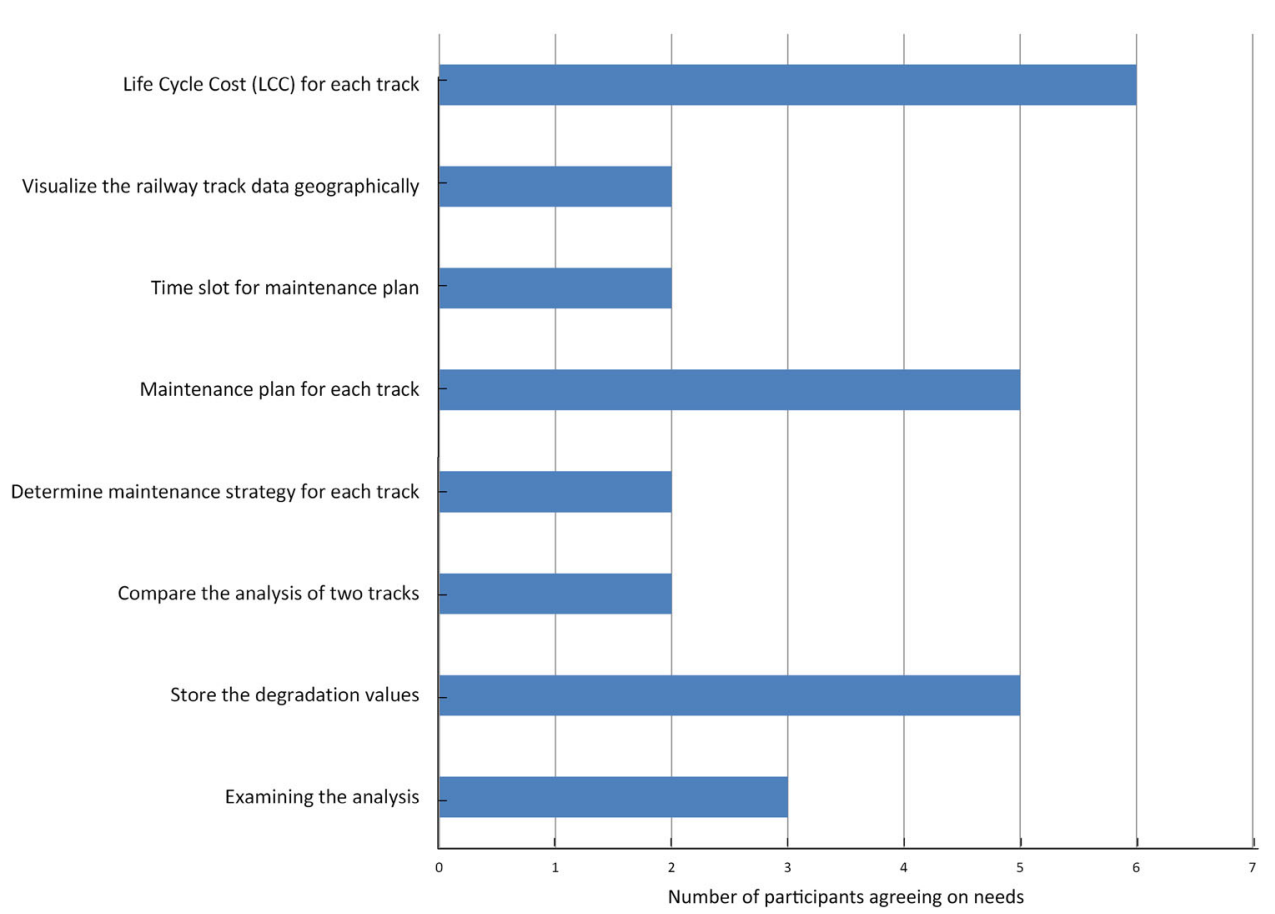

Fig. 11 Condition-based maintenance stakeholders' agreement on needs

stakeholders to connect the results of the analysis with the track infrastructure. However, visualising the track can help analysis and decision-making stakeholders to determine the more seriously affected areas by offering a clear picture and facilitating comparisons with other track sections at the same time. A clear picture of the track will show the influence of various factors on the track status. Also, it makes easier to understand how they influence one another. This technology has the ability to examine individual aspects of the tracks and would provide evidence to justify decisions to funders and policy makers.

\subsubsection{Track life cycle cost (LCC)}

Determine life cycle cost (LCC) for each track. This requires a comparison of different maintenance, intervention, and renewal strategies for track sections based upon the costs and risks over a period of time. Track deterioration modelling techniques are used to evaluate the deterioration processes for sleepers, transport loadings, track alignments, lengths of radius, the operational speed, sublayer conditions to renew the track structure. However, the track LCC model inputs are initial track condition data, intervention triggers, uplift effects, and the cost of interventions and environmental impacts. LCC's effective decision supports system for maintenance of the railway track. At the same time, the output cost takes into account all factors associated with the lifetime of the system, such as operating costs, maintenance costs, and energy costs. The maintenance cost plays an important role in track infrastructure. The cost of maintenance of LCC track infrastructure has two different levels of uncertainty. Costs are due either to such factors as train delay, traffic disruption or derailment, or to the reliability and maintainability of the track. The main issue for decision-making stakeholders is determining the tamping cost. Hence, it is necessary to order tamping and set up the cost for about a year. Therefore, Trafikverket wants to connect the life cycle costs within certain areas needing maintenance, e.g. tamping. Ultimately, determining the life cycle cost for the track will be based on the equipment needing maintenance.

Figure 11 shows the interviewees' agreement on needs. Many stakeholders want LCC, a maintenance plan for each track and the ability to store values after the analysis. However, two of Trafikverket's condition-based maintenance stakeholders want a maintenance strategy for each track; they want to compare the analysis of two tracks at the same time, clearly visualise the track on a geographical map, and ascertain a time slot for each maintenance plan. Achieving these needs will improve railway track performance, facilitate the analysis of the track, and help predict the future state of the track.

\section{Conclusion}

The purpose of this study was to investigate the needs of maintenance stakeholders and to find out if the stakeholders' knowledge needs are satisfactory. The results showed that problems with data measurement and analysis should be dealt 
with specific needs for more consistent data and information that can assist them in maintenance decisions. These needs are:

- Positioning irregularities of measured data made it difficult to determine where maintenance activities were to be conducted.

- Over 30 railway track parameters are measured but only five show to be significant for track irregularities. Degradation of these affects safety.

- Long-term maintenance strategy is lacking, therefore, only arbitrary judgement and historical data are used to plan maintenance actions.

- Limitations in analysis of data since the software and data sources are not compatible with each other.

- Missing data, even when measurements are conducted regularly on the track sections. It is not known why the information is lost or missing.

In addition to the problems, areas of improvement were found. These are:

- The maintenance of the railway tracks needs to integrate proactive solutions in order to reach the desired goals of improved safety, improved availability, and improved reliability. This includes analyses based on the calculated values to understand the process of track degradation and what needs to be done to improve maintenance decisions.

- Develop a visualisation tool that shows the railway track geographically, using both mile markers and GPS coordinates, for information concerning track quality. This mapping should show the track parts clearly and be used to facilitate the connection between the results and the track infrastructure. This is to also include maintenance windows (time slots), which are crucial in assisting the estimation of maintenance actions.

- Develop Life cycle cost (LCC) model for track degradation where maintenance interventions can be compared with different interventions and maintenance strategies.

These findings are applicable for the Swedish railway network in that the areas with specific problem and the areas chosen for improvement are critical for maintenance decisions. For good decision support, it is necessary to use accurate condition monitoring data, from all sources, to gain a complete understanding of the railway network. And then a more longterm strategy can be set up which can then support a LCC model for railway infrastructure. For that to occur, a more specific development, in the areas of condition monitoring data collection and in the development of analysis models, is needed. When these are complete, track degradation models necessary for a LCC model, with clear input definitions for data, triggers, uplift effect, cost, and environmental impacts can be developed. In conclusion, by applying the knowledge gained in this study, railway track availability can be increased, as well as, operation and maintenance costs can be reduced.
Limitations of this study are that there were a limited number of interviews conducted, although key people were chosen, and that only Optram was studied. It is true that there are other systems used in the railway network. Even if some do report more accurate data they do not specifically deal with track condition data. Additionally, by analysing several systems together, a better understanding of the whole rail network could be possible; however, this study does show where improvement work should begin.

Open Access This article is distributed under the terms of the Creative Commons Attribution 4.0 International License (http:// creativecommons.org/licenses/by/4.0/), which permits unrestricted use, distribution, and reproduction in any medium, provided you give appropriate credit to the original author(s) and the source, provide a link to the Creative Commons license, and indicate if changes were made.

\section{Appendix}

The questions focus on two main areas:

(a) Identify the problem.

(b) Define the stakeholders needs.

\section{Data}

(1) What do you think of the data accuracy? Why?

(2) Is the contractor responsible for assuring the accuracy or only for data gathering? How?

(3) How can the contractor assure the quality of data? In each point give me an example.

\section{Parameter}

(4) What are the parameters that are more sufficient and important? Why?

\section{Problems}

(5) What are the problems recognised after analysis?

(6) What are the problems that exist in different areas such as functionality and data? (As an end-user)

\section{Needs}

(7) What analysis is needed within and does it not exist now? Why? and How?

8) What is needed to improve the prediction? Why? and How? 


\section{References}

1. Nissen A (2009) Development of life cycle cost model and analyses for railway switches and crossings. Lulea University of Technology

2. Svensson N, Eklund M (2007) Screening of environmental pressure from products in the Swedish railway infrastructure: implications for strategic environmental management. Resour Conserv Recycling 52(2):248-265

3. Tzanakakis K (2013) The railway track and its long term behaviour: a handbook for a railway track of high quality. Springer Science \& Business Media, Berlin

4. Esveld C (2001) Modern railway track

5. Indraratna B, Salim W, Rujikiatkamjorn C (2011) Advanced rail geotechnology-ballasted track. CRC Press, Balkema

6. Murthy DP, Kobbacy KAH (2008) Complex system maintenance handbook. Springer, New York

7. Karim R (2008) A service-oriented approach to e-maintenance of complex technical systems. Luleå University of Technology, Division of Operation and Maintenance Engineering

8. IEC (2004) 60300 (3-14): Dependability management-Part 3-14: Application guide Maintenance and maintenance support

9. Kumar U, Nissen A, Schunnesson H et al (2010) Operational Safety and Maintenance. LTU, Luleå

10. Crespo Márquez A (2007) The maintenance management framework: models and methods for complex systems maintenance. Springer Verlag, London

11. Iman Ak (2013) Cost-effective maintenance of railway track geometry: a shift from safety limits to maintenance limits, Luleå tekniska universitet

12. Asplund M (2014) Wayside Condition Monitoring Technologies for Railway Systems, Luleå tekniska universitet

13. Schunnesson H, Juntti U, Nissen A et al (2013) Evaluation of track geometry maintenance for heavy haul railroad in Sweden-a case study. Proc Inst Mech Eng Pt F: J Rail Rapid Transit:0954409713482239

14. Bergquist B, Söderholm P (2014) Data analysis for conditionbased railway infrastructure maintenance. Qual Reliabil Eng Int

15. Sadeghi J, Askarinejad H (2010) Development of improved railway track degradation models. Struct Infrastruct Eng 6(6):675-688

16. Vale C, Ribeiro IM (2014) Railway condition-based maintenance model with stochastic deterioration. J Civ Eng Manag 20(5):686-692

17. Karim R, Candell O, Söderholm P (2009) E-maintenance and information logistics: aspects of content format. J Qual Maint Eng 15(3):308-324

18. Haseloff S (2005) OPUS-Context Awareness in Information Logistics

19. Candell O, Karim R, Söderholm P (2009) eMaintenance-information logistics for maintenance support. Robot Comput Integr Manuf 25(6):937-944

20. Gutsche K, Böhm T (2011) e-Maintenance of railway assets based on a reliable condition prediction. Int $\mathrm{J}$ Perform Eng 7(6):573

21. Söderholm P, Holmgren M, Klefsjö B (2007) A process view of maintenance and its stakeholders. J Qual Maint Eng 13(1):19-32

22. Sloderholm P (2005) Maintenance and continuous improvement of complex systems: linking stakeholders requirements to the use of built-in test systems
23. Espling U, Kumar U (2008) Benchmarking of the maintenance process at Banverket (the Swedish National Rail Administration). In: Anonymous Complex System Maintenance Handbook. Springer, pp 559-583

24. Chiacchiari L, Loprencipe G Measurement methods and analysis tools for rail irregularities: a case study for urban tram track. J Mod Transport:1-11

25. Pingrui Z, Xueyi L, Guan L (2014) Experimental study of temperature gradient in track slab under outdoor conditions in Chengdu area. J Mod Transport 22(3):148-155

26. Lander S, Petersson J (2012) Tamping planning in railway maintenance: improvement potential for optram as decision support

27. Chiacchiari L, Loprencipe G Measurement methods and analysis tools for rail irregularities: a case study for urban tram track. J Mod Transport:1-11

28. Swedish Standards Institute (2001) Maintenance Terminology. Research Report SS-EN 13306

29. Holmberg K, Adgar A, Arnaiz A et al (2010) E-maintenance. Springer Publishing Company Incorporated, New York

30. Patra A, Söderholm P, Kumar U (2009) Uncertainty estimation in railway track life-cycle cost: a case study from Swedish National Rail Administration. Proc Inst Mech Eng Pt F: J Rail Rapid Transit 223(3):285-293

31. International Electrotechnical Commission (2005). Dependability management. Part 3-3: Application guide-life cycle costing

32. MAINLINE (2014) MAINtenance, renewal and Improvement of rail transport iNfrastructure to reduce Economic and environmental impacts SST.2011.5.2-6. http://www.mainline-project.eu/

33. Randall RB (2011) Vibration-based condition monitoring: industrial, aerospace and automotive applications. John Wiley \& Sons, Chichester

34. Utne I, Brurok T, Rødseth H (2012) A structured approach to improved condition monitoring. J Loss Prev Process Ind 25(3):478-488

35. Bergquist B, Söderholm P (2014) Control Charts supporting Condition-Based Maintenance of Linear Railway Infrastructure Assets. In: Anonymous Proceedings of the 3rd international workshop and congress on eMaintenance: June 17-18 Luleå, Sweden: eMaintenance, Trends in technologies \& methodologies, challenges, possibilites and applications. Luleå: Luleå tekniska universitet

36. Granstrlom R (2005) Maintenance for improved punctuality: a study of condition monitoring technology for the Swedish railway sector

37. Jagersma PK, Jagersma PK (2011) Competitive information logistics. Business Strategy Series 12(3):136-145

38. Kajko-Mattsson M, Karim R, Mirjamsdotter A (2010) Fundamentals of the eMaintenance Concept. In: Anonymous 1st international workshop and congress on eMainteance, p 22

39. Lee J, Ni J, Djurdjanovic D et al (2006) Intelligent prognostics tools and e-maintenance. Comput Ind 57(6):476-489

40. Candell O, universitet Lt (2009) Development of Information Support Solutions for Complex Technical Systems Using EMaintenance. Division of Operation and Maintenance Engineering, Luleå University of Technology

41. Yin RK (2014) Case study research: design and methods. Sage publications, Thousand Oaks 